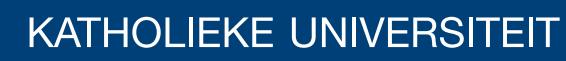 \\ LEUVEN
}

\section{Faculty of Business and Economics}

0 HDVXUQJ[FRQUDJIRQLQNAXH

( XLRSHDQNRYHHJUQERQGP DUNM

\&KDIOMIO DUKDV

DEPARTMENT OF DECISION SCIENCES AND INFORMATION MANAGEMENT (KBI) 


\title{
MEASURING CONTAGION IN THE EUROPEAN SOVEREIGN BOND MARKET*
}

\author{
Charles MATHIAS ${ }^{\dagger \ddagger}$
}

May 2012

\begin{abstract}
I propose a simple econometric model to capture the interaction between commonness and idiosyncrasy in returns on sovereign bonds of Eurozone countries. Common contagion is defined as the impact of yesterday's idiosyncratic shocks on today's common factor. When assuming returns are driven by one common factor, the model shows the presence of common contagion during 2010. This picture is nuanced when assuming two-factor model, where the two factors are identified as a safe and a troubled economy factor. The common contagion identified in the one-factor model corresponds to the impact of safe country shocks on the troubled economies. Hence, although government bonds of safe and troubled economies are very interlinked, one cannot conclude that the troubled economies have been contagious on the safe ones.
\end{abstract}

${ }^{*}$ I am grateful to Kris Boudt, Christophe Croux, Geert Dhaene, Michael Froemmel, Hugues Pirotte and David Veredas for useful comments.

${ }^{\dagger}$ Faculteit Economie and Bedrijfskunde, KULeuven, Email: charles.mathias@econ.kuleuven . be. Address: Naamsestraat 69, B-3000 Leuven, Belgium. Phone: +3216326968.

${ }^{\ddagger}$ ECARES, Solvay Brussels School of Economics and Management, Université libre de Bruxelles and ECORE. Email: charles.mathias@ulb.ac.be. Address: Avenue F. D. Roosevelt 50 (CP 139), B-1050 Brussels, Belgium. Phone: +3226504133 . 


\section{Introduction}

European sovereign bond markets between 2007 and 2011 have been characterized by an interesting schizophrenia. Given the large financial interdependence of European Monetary Union (henceforth EMU) countries on the one hand, but the fundamental economic differences between these countries on the other hand, I suspect the sovereign bond yields to exhibit a peculiar coexistence of comovement and idiosyncrasy. The question whether, on top of the sensitivity of all countries to market shocks, idiosyncratic news in some countries affects the entire market of European sovereign bond yields, raises an interesting econometric challenge. The present paper proposes a model to capture these dynamics.

The signature in 1992 of the Maastricht Treaty, aiming to introduce a common European currency seven years later, dramatically altered the economic dynamics on the old continent. The theory of optimal currency areas, greatly influenced by [8], states that the viability of the geographic perimeter of a currency depends on the economic homogeneity of that area. The different regions of an optimal currency area should be in similar economic shape, with close inflation and unemployment rates, productivity indicators, current account balances or private and public debts. Moreover a common economic policy should ensure that any such regional difference can only by temporary, such that there is convergence and no divergence. In 1992, the European Union was far from meeting these requirements: economic differences between countries were very large and national governments had full discretion over the economic and fiscal policy followed. Therefore, the raison d'être of the Maastricht Treaty was to adopt common goals for all countries, in terms of inflation rates (no more than 1.5 percentage points higher than the average of the three lowest inflation member states of the EMU), government finance (public deficit of maximum 3\% of GDP and public debt of maximum 60\% of GDP), exchange rates (national governments were not allowed to devalue their currencies) and long-term interest rates (nominal long-term interest rates were not allowed to be more than 2 percentage points higher than in the three lowest inflation member states) - these goals were to be met by national governments to be allowed to join the Euro-zone. Even though ten years later only Luxembourg met all requirements, and a country as Greece did not meet any of them, it was nevertheless decided to engage into the creation of the single currency with elven countries: Austria, Belgium, Finland, France, Germany, Ireland, Italy, Luxembourg, the Netherlands, Portugal and Spain. Greece was allowed to jump on board in 2001, two years after the euro was launched, even though it did not meet the initial requirements.

Since the introduction of the common currency, European sovereign bond markets have been characterized by a very high comovement. The appearance of such comovement for short term rates is quasi mechanical, given that the European Central Bank sets the short term base rates for the entire Euro-zone. On the long end of the yield curve, however, high covariation is much less straightforward. Indeed, long term government bond yields are greatly impacted by investors' perception of the country's creditor quality. Even with a unified currency, there were still huge differences within Europe on that front, given for example the differences in debt-to-GDP and public deficit-to-GDP ratios, or the differences in national inflation rates. Moreover, the Maastricht Treaty did not foresee any bailout clause, under which a country 
defaulting on its debt would automatically be saved by the others, instead of having to leave the EMU and launch a new national currency to would devalue the nominal debt. Therefore, one could say that markets perceived the default (or exit) risk of all European countries to be very close to each other, even though in due course there were still fundamental differences between the countries and there was no common European economic policy which would ensure the convergence of the different economies.

The financial market turmoil starting in 2007 would put these fundamental differences on the table again. On the one hand, the increased uncertainty and reduced economic activity immediately showed the vulnerability of some countries, such as Greece. Even before the crisis, Greece had a public debt of around 100\% of its GDP and was running a structural deficit-this became very clear when the Greek government admitted that official statistics did not reflect reality. The little flexibility of the Greek labour market made it very difficult for the country to provide a good answer to this economic downturn. Also Portugal and Italy were in a similar case as Greece. On top of that, some other EMU countries such as Ireland or Spain were facing an implosion of housing bubbles. Ireland was hit particularly hard by the crisis, not only because banks had to be bailed out, but also because the bulk of its government incomes were directly or indirectly linked to rising house prices. On the other hand, the outburst of the financial crisis did not only show which countries were vulnerable, but also which countries had a strong underlying economy, and were able resist against these external negative shocks, such as Germany, the Netherlands and Finland.

The increased understanding of differences in country's default probabilities, combined with messages that Germany or the International Monetary Fund would not organize a massive bailout but only provide limited financial help conditional on structural reforms, increased the perception that EMU countries in difficulty might leave the Euro-zone to devalue from the Euro. This generated a decoupling on the financial markets in the trading on long term government bonds. Whereas at the end of 2007 the latter was characterized by a very high comovement (the first principal component captured more than $85 \%$ of average bond return variance), the weaker countries such as Greece, Ireland and Portugal, started to exhibit rising government bond yields, who behaved ever more independently from the safer countries such as Germany.

Given this coexistence of independence and interdependence of EMU countries, one may wonder what is the exact nature of the commonness and the idiosyncrasy happening in the European sovereign bond markets. Indeed, although there are fundamental economic differences between the countries, and although there is no common European policy, the different countries still share the same currency. The link between countries as Germany and Greece is thus complex: on the one hand Germany would loose by bailing Greece out, but on the other hand it might loose even more by allowing it to default or leave the EMU. Given this situation, the distinction between commonness an idiosyncrasy in the European sovereign bond market might not be that straightforward. More specifically, if investors truly believe that the Greek or Portuguese crisis are a threat to the single currency, one would expect bad news in these countries to have a bad impact on all other countries. Therefore, an interesting question is to understand whether idiosyncratic news of one EMU country affects the entire Euro-zone, and 
how this effect would be evolving through time.

In the economic theory, the question of correlations between idiosyncratic components is covered by the literature on contagion, which is central in the understanding of a financial crisis. Contagion is a fairly recent research subject, which seriously developed in the aftermath of the Asian crisis of 1997. Although contagion is an elusive concept, and several definitions can be given to it, all of them share the intuitive idea that contagion comes to the surface through an increase in correlations. As it is very well documented in [5] and [4], the main idea of detecting contagion in the present econometric literature is to find an unexplained increase in contemporaneous correlations. This means that one assumes that comovement should entirely be explained according to a given factor model, and that all comovement not explained by that model is contagion.

I however argue that there are two main weaknesses in focusing on contemporaneous correlations. First, it is cumbersome to identify the direction of contagion, since one needs to tackle issues of endogeneity to identify simultaneous causality. Second, in a latent factor model, which is the approach of [4], one discards the possibility that increased comovement is the result of increased common shocks variance, since one needs to impose that common shocks have the same variance before and during the crisis.

The present paper aims at overcoming these weaknesses by defining contagion as the impact of a country's previous day idiosyncratic shocks. This not only allows to identify the direction of contagion without having to deal with endogeneity, but it also leaves in the middle whether an increase in contemporaneous correlations is the result of contagion or of increased common shock variance. On top of this, I introduce the distinction between common and idiosyncratic contagion. The former denotes the effect of yesterday's idiosyncratic shocks on today's common factor, whereas the latter refers to the impact of these idiosyncratic shocks on the country-specific component.

The model is applied on daily returns on the ten-year government bonds of the 11 Eurodenominated countries (all founding members of the single currency but Luxembourg, plus Greece) between 2008 and 2011. A one- and a two-factor model are considered. In the former, observations load on one common factor which is the sum of a contemporaneous common shock and of the effect of previous day idiosyncratic shocks. In the latter, I distinguish between a safe and a troubled economy factor, which behave similarly as in the one-factor model, except that they are allowed to mutually exercise contagion on each other. The model is estimated on rolling windows of length one year, which avoids having to determine a starting date of the crisis.

Estimation of the one-factor model shows that contagion dynamics were very mild before 2009 and that common contagion was non existing. After the first trimester of 2009, however, common contagion dynamics represented around $10 \%$ of total bond return variation. The major contributors to contagion were Italy, Portugal, Spain, Ireland and France-surprisingly enough Greece only contributed little to contagion variance. This suggests the investors' conviction that, although Greece greatly depends on decisions of the European Union, the Eurozone as a whole would survive even without Greece. 
The two-factor model provides an interesting completion of the one-factor model. The model is identified such that Germany does not load on the second factor, which is consistent with the idea that there is comovement with Germany, and comovement in the spread with respect to Germany. The model clearly shows the idea of divergence: countries such as Greece, Portugal and Spain have exhibited gradually decreasing loadings on the safe economy factor, going from positive in early 2008 to very negative by 2011. This illustrates that more is going on than just decoupling: market news can be good for some countries and bad for others. Moreover, only risky countries load on the second factor. The only source of contagion in the two-factor model is one coming from the first to the second common factor: that is, when the German yield goes down, this causes spreads to go up the next day. The reverse is however not true: when spreads go up, the German yield does not go down. The two-factor model therefore shows that the interdependence of European sovereign bonds has been very important, but that there has not been any large contagion from more to less risky countries.

The remainder of the paper is organized as follows. Section 2 reviews literature on measuring contagion. Section 3 presents the dataset used and shows descriptive statistics. Sections 4 and 5 respectively present the one- and two-factor model. Section 6 concludes.

\section{The econometrics of contagion}

Although relatively recent, literature on contagion has been booming over the last decade. Very much influenced by the Asian crisis of 1997, most of the literature focuses on equity and foreign exchange markets. Extensively reviewing this literature goes beyond the scope of the present paper, but [9] provide an interesting view by proposing five different definitions of contagion from a country covariation perspective. First, contagion could be defined as an increase of the probability of a crisis in one country, conditional on a crisis in another country. Second, one could look at contagion as being an event happening when volatility of one country spills over to the other's volatility. Third, contagion could be understood as excess cross-country comovement, i.e. comovement that cannot be explained by fundamentals. Fourth, one may define contagion as a significant increase in correlations conditional on a crisis event. Finally, contagion could mean an intensification of transmission channels. In the econometric theory, most of the contributions on measuring contagion have focused on the fourth definition of [9].

The literature on measuring contagion is extensively reviewed by [5] and [4]. The main idea is to compare contemporaneous correlations before and during the crisis, and to associate a significant increase in correlations with contagion. Some contributions deserve particular attention. [2] and [3] detect contagion by assuming that data follow a factor model where the factor has the same variance before and during the crisis. Any observed additional comovement during the crisis compared to before is then associated with contagion. [7] propose a bivariate test for contagion. They also compare correlations before and during the crisis, but take into account the spurious effect on correlations of increased volatilities in times of market 
turmoil. [6] and [1] perform a similar test as [2] and [3], but they focus on the correlations happening at extreme movements.

The present paper will take a fairly different stance on contagion.

First of all, I will not look at contemporaneous but at lagged correlations, by defining contagion as the Granger causality of previous day idiosyncratic shocks on today's observations. This avoids having to make several model assumptions. On the one hand, one does not have to impose a start date of the crisis and one does not have to make the assumption that the common factor variance is constant throughout the whole period. Intuitively, it remains difficult to support such an assumption of stationarity over a period which seemingly is characterized by a change of regime. I will therefore leave in the middle whether an increase in contemporaneous correlations is originated from contagion in the sense of [4], or from larger common shocks. On the other hand, one can explicitly identify the direction of contagion without having to deal with endogeneity. When looking at the contemporaneous impact of idiosyncratic shocks, one faces the issue of simultaneous causality, which can only be resolved by imposing additional model assumptions. Therefore, I believe that looking at the impact of previous day shocks is closer to the intuitive idea of contagion.

Second, I will distinguish between common and idiosyncratic contagion. Common contagion is defined as the causal impact of previous day idiosyncratic shocks on today's common factor-in a way, it is the average impact of contagion. Idiosyncratic contagion refers to the impact of idiosyncratic shocks on the idiosyncratic components, which can by definition of idiosyncrasy only be on a limited number of countries. This distinction will allow me to evaluate whether some countries generate contagion towards the European economy as a whole.

\section{Dataset}

Daily yields of 10-year zero-coupon government bonds for 11 Euro countries-Austria, Belgium, Finland, France, Germany, Greece, Ireland, Italy, the Netherlands, Portugal and Spainbetween October 27th, 2007 until July 31st, 2011, are downloaded from Bloomberg. Figure 7 plots the evolution of the yields during the considered period, for all countries and for the cross-sectional average. The average shows a pretty flat path, until January 2011, when the crisis in Greece, Ireland and Portugal significantly sharpened. Until the end of 2010, Austrian, Belgian, Finnish, French, German and Dutch yields were subject to a downward trend, possibly as a result of flight to quality dynamics against Greece, Portugal and Ireland. Italian yields also decreased during the same period, be it mildly_Spanish yield remained fairly constant. In December 2010, the yields of all countries went up. By March 2011, Greek, Irish, Portuguese, Spanish and Italian bonds lost terrain, while sovereign yields in Austria, Finland, France, Germany and the Netherlands went down again. Belgium and France did not follow this trend.

As can be graphically be seen in Figure 7 in the appendix, data do not seem to have finite means and variances, which raises the issue of stationarity. I deal with this by working with 
$\log$ returns on bond prices instead of prices or yields. If $y_{i, t}$ is the yield of country $i$ at time $t$, denote by $p_{i, t}$ the price of a 10-year zero-coupon bond with yield $y_{i, t}$ :

$$
p_{i, t}=\frac{1}{\left(1+y_{i, t}\right)^{10}}
$$

Define $r_{i, t} \equiv \log \left(p_{i, t}\right)-\log \left(p_{i, t-1}\right)$ the $\log$ return on that bond. This means the focus will be on differences rather than on levels. Intuitively the choice of log returns means that I assume log bond prices to be integrated of order one. If one suspects prices to be integrated by a different order, this order would have to be estimated, which is cumbersome and would probably add little to the object of this study, which is contagion.

A second issue of stationarity is that of constant parameters through time: it is very difficult to assume that the entire four-year period has been free of change of regimes on the parameters. Therefore, I will estimate the model to be presented in Sections 4 and 5 on overlapping subsamples. I create windows of length one-year (approximately 250 observation dates), where at each new window I take a jump of one quarter, i.e. neighbouring windows have an overlap of three quarters. This means that I assume stationarity in each window ex ante, even though these windows may contain structural breaks. An ex post observation of the evolution of parameters on the different subsamples will naturally suggest for which subsamples the stationarity assumption does not hold. ${ }^{1}$

Tables 1, 2 and 3, and Figure 1 show descriptive statistics of $r_{i, t}$ 's for each subsample. Table 1 shows average daily bond returns in each sub-sample. The upper plot of Figure 1 shows the same data. This plot is coherent with Figure 7-average returns for Greece significantly dropped at the beginning of 2010, followed by Portugal and Ireland, and a bit later by a general downward movement for all countries, particularly severe in Spain and Italy. Table 2 represents the standard deviations per country for each one-year window; the same data are plotted in the middle panel of Figure 1. The years 2008 and 2009 are characterized by very low and similar standard deviations for all countries; only Greece and Portugal are slightly larger than the others. In 2010, the standard deviation of Greece exploded compared to other countries. Also Portugal and Ireland experienced significant increases, as well as Spain. Standard deviations of all other countries are lower than in 2008 and 2009. Finally, since I am interested in co-movement of bond returns, Table 3 shows the variance decompositions arising from a PCA on each sub-sample's panel. For each subsample, it shows what percentage of total variance that is captured by each principal component. The final plot of Figure 1 graphically shows this evolution by focusing on the first three principal components: it shows which share of total variance being captured by the first, the second and the third principal component. Clearly, 2008 and 2009 were characterized by much more co-movement than 2010 and 2011. Moreover, whereas a one-factor model seems most appropriate for 2008 and 2009, 2010 and 2011 seem to behave more like a two-factor model. Both alternatives of a one- and two-factor model will be considered in the next Sections.

\footnotetext{
${ }^{1}$ Moreover, it would be possible to develop a test statistic to perform rigorous inference on the stationarity issue within each window, by comparing the parameter values in two distinct windows and taking into account standard errors. Such test however goes beyond of the present paper, given that its objective is mainly descriptive.
} 


\section{Figure 1: Descriptive statistics of sovereign bond log returns}

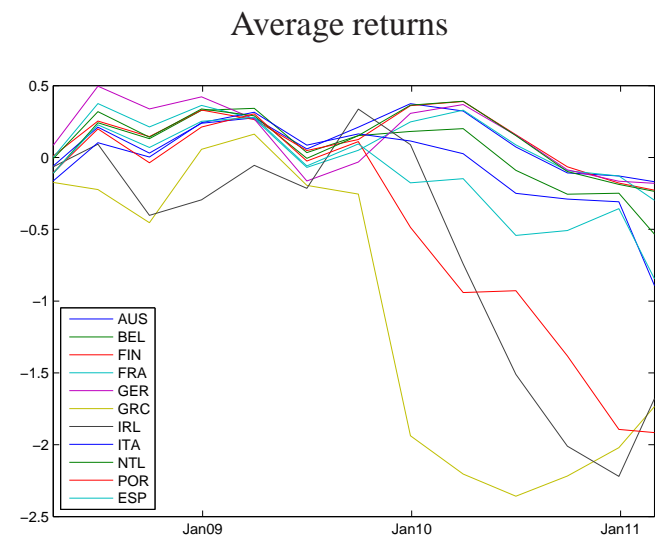

Standard deviation of returns

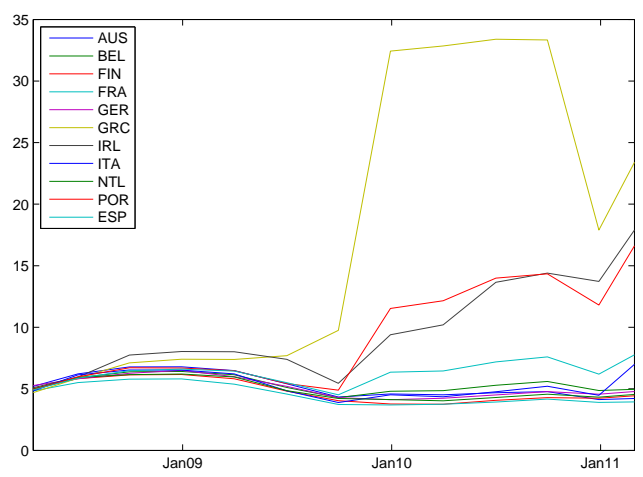

Variance decomposition

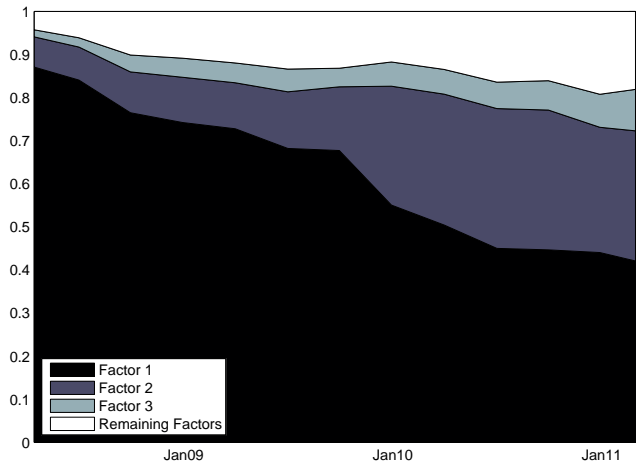

The top chart shows the evolution, per subsample, of the arithmetic average of rescaled bond returns $10^{3} \times r_{i, t}$, as represented in Table 1. The middle chart represents subsample standard deviations, available in Table 2. The down chart finally shows the variance decompositions arising from a PCA on the bond returns in each subsample. Data are available in Table 3, but only the variance decompositions of the first three principal components are shown in the Figure-components 4 to 11 are regrouped. 


\section{A one-factor model}

\subsection{The model}

For a given subsample, let $x_{i, t}$ denote the daily bond return of country $i$ on day $t$, demeaned over time. In the one-factor model, I let the panel of $x_{i, t}$ 's behave according to the following equation,

$$
x_{i, t}=\beta_{i} \phi_{t}+\zeta_{i, t},
$$

where $\phi_{t}$ is an (unobservable) market factor and $\beta_{i}$ the loading of country $i$ on that factor. Country-specific dynamics of country $i$ are captured by $\zeta_{i, t}$. Both the market factor $\phi_{t}$ and the country-specific terms $\zeta_{i, t}$ will be allowed to suffer from contagion arising from previous day idiosyncratic news. Therefore, I model $\phi_{t}$ to be the sum of a contemporaneous common shock $v_{t}$, where $\mathrm{E}_{t-1}\left[v_{t}\right]=0,{ }^{2}$ and the effect of all previous day idiosyncratic shocks:

$$
\phi_{t}=v_{t}+\sum_{k=1}^{n} \gamma_{k} u_{k, t-1} \text {. }
$$

In the same spirit, the country-specific component $\zeta_{i, t}$ is modelled as the sum of a contemporaneous idiosyncratic shock $u_{i, t}$, where $\forall i: \mathrm{E}_{t-1}\left[u_{i, t}\right]=0$, and the effect of all previous day idiosyncratic shocks:

$$
\zeta_{i, t}=u_{i, t}+\sum_{k=1}^{n} \delta_{k i} u_{k, t-1} .
$$

It is very important to observe that the market factor $\phi_{t}$ and the idiosyncratic term $\zeta_{i, t}$ do not satisfy the orthogonality conditions as defined in [10], since $\forall i: \mathrm{E}\left[\phi_{t} \zeta_{i, t}\right] \neq 0$. Common and idiosyncratic shocks $v_{t}$ and $u_{i, t}$, however, do satisfy well defined orthogonality conditions, since it is assumed that $\forall i, j \in\{1, \ldots, n\}$ and $\forall t, s \in \mathbb{Z}: \mathrm{E}\left[u_{i, t-s} u_{j, t}\right]=0, \mathrm{E}\left[u_{i, t-s} v_{t}\right]=0$ and $\mathrm{E}\left[v_{t-s} v_{t}\right]=0$.

The $\gamma_{k}$ 's and $\delta_{k i}$ 's of (2) and (3) measure the Granger causality coefficient of country $k$ 's idiosyncratic shocks on $\phi_{t}$ and on $\zeta_{i, t}$ respectively. This Granger causality is interpreted as contagion of country $k$-specific news: $\gamma_{k}$ 's measure common contagion, whereas $\delta_{k i}$ 's measure idiosyncratic contagion. Three comments apply when defining contagion from this Granger causality perspective. First, no explicit difference is made between negative and positive idiosyncratic shocks. This implies that, in the present setting, the notion of contagion is not associated with the impact of negative news only. Second, contagion is not conditioned on extreme movements - small and large idiosyncratic shocks are assumed to have the same proportional impact on the common factor. Finally, the coefficients are allowed to be both positive or negative - the sign will alter the effect on the variance of the common factor $\phi_{t}$, given by $\operatorname{var}\left(\phi_{t}\right)=\sigma_{v}^{2}+\gamma^{\prime} \Sigma_{u} \gamma$. When they are positive, idiosyncratic shocks have a variance increasing effect. This case corresponds to the usual notion of contagion and will be referred to as

\footnotetext{
${ }^{2}$ The notation $\mathrm{E}_{t-1}[\cdot]$ denotes conditional expectation, i.e. expectation conditional on information $\mathcal{I}_{t-1}$ available at $t-1: \mathrm{E}_{t-1}[\cdot] \equiv \mathrm{E}\left[\cdot \mid \mathcal{I}_{t-1}\right]$.
} 
such, or by speaking of positive contagion. Positive contagion also has the effect of increasing the overall correlations in the panel, which is coherent with the mainstream definitions of contagion cited in the introduction. When coefficients are negative, idiosyncratic shocks will have a variance reducing effect on the total panel; this case is called inverse or negative contagion. The sign of the contagion coefficient can be understood from a portfolio management perspective: the riskiness of a country corresponds to the degree at which it increases/decreases the portfolio variance.

\subsection{Estimation procedure}

By denoting $\mathbf{x}_{t} \equiv\left(x_{1, t}, \ldots, x_{n, t}\right)^{\prime}$ and $\mathbf{u}_{t} \equiv\left(u_{1, t}, \ldots, u_{n, t}\right)^{\prime}$, the model defined by (1), (2) and (3) can be rewritten as

$$
\mathbf{x}_{t}=\boldsymbol{\beta} v_{t}+\mathbf{u}_{t}+B \mathbf{u}_{t-1},
$$

where $\boldsymbol{\beta}=\left(\beta_{1}, \ldots, \beta_{n}\right)^{\prime}$ and $B=\boldsymbol{\beta} \boldsymbol{\gamma}^{\prime}+\Delta$, with $\boldsymbol{\gamma}=\left(\gamma_{1}, \ldots, \gamma_{n}\right)^{\prime}, \Delta=\left(\boldsymbol{\delta}_{1}, \ldots, \boldsymbol{\delta}_{n}\right)$ and $\boldsymbol{\delta}_{i}=\left(\delta_{1 i}, \ldots, \delta_{n i}\right)^{\prime}$. Differently stated, (4) is a factor model in the sense of [10], with a static common component $\boldsymbol{\chi}_{t}=\boldsymbol{\beta} v_{t}$, but with dynamic idiosyncratic components $\boldsymbol{\xi}_{t}=\mathbf{u}_{t}+B \mathbf{u}_{t-1}{ }^{3}$ Estimation of (4) is a problem of $2 n+n^{2}+n(n+1) / 2+1$ unknowns. Indeed, $\boldsymbol{\beta}$ and $\boldsymbol{\gamma}$ are both $n$-dimensional parameters to estimate, $\Delta$ contains $n^{2}$ parameters, $\Sigma_{u} \equiv \operatorname{var}\left(\mathbf{u}_{t}\right)$ contains $n(n+1) / 2$ parameters and $\sigma_{v}^{2} \equiv \operatorname{var}\left(v_{t}\right)$ is a one-dimensional parameter.

Some identification constraints are imposed. For the exact estimation of the factor model, I will impose that $\boldsymbol{\beta}^{\prime} \boldsymbol{\beta}=n$, which means that the factor loadings do not contribute to the average variance of the time series. For the identification of common $v$ s. idiosyncratic contagion, I will assume that a weighted average of idiosyncratic contagion effects is zero, where the weights used for each country are proportional to its common factor loading. That is, $\forall i: \boldsymbol{\beta}^{\prime} \boldsymbol{\delta}_{i}=0$. Since $B=\boldsymbol{\beta} \boldsymbol{\gamma}^{\prime}+\Delta$, this identification constraint will make the estimation of $\gamma$ and $\Delta$ straightforward.

Estimation of (4) will be done in three steps.

First, I apply the static factor model of [10] to the panel of $\mathbf{x}_{t}$ 's, i.e. I write $\mathbf{x}_{t}=\mathbf{b} \tilde{f}_{t}+\mathbf{e}_{t}$, where $\tilde{f}_{t}$ is the first principal component of the panel and $\mathbf{b}$ the factor loadings, estimated by diagonalizing the observed variance-covariance matrix of $\mathbf{x}_{t}$ 's. The estimates $\widehat{v}_{t}$ and to $\widehat{\boldsymbol{\beta}}$ are then obtained by rescaling $\tilde{f}_{t}$ and $\mathbf{b}$, such that $\widehat{\boldsymbol{\beta}}^{\prime} \widehat{\boldsymbol{\beta}}=n$. The idiosyncratic components of the static factor model are the estimates of the idiosyncratic components in (4): $\widehat{\xi}_{t}=\mathbf{e}_{t}$.

Second, I estimate the $\operatorname{VMA}(1)$ representation of the estimators of $\boldsymbol{\xi}_{t}$ as obtained in the previous step. Estimating a Vector Moving Average is always a delicate exercise: the explanatory variables are not observed and therefore need to be estimated themselves. The Wold Theorem however states that one can express a Vector Moving Average of finite order as a Vector Autoregressive Model with infinite lags $\operatorname{VAR}(\infty)$. Since I work with returns and that

${ }^{3}[10]$ still holds even with auto- and cross-correlated idiosyncratic terms. Indeed, assumptions M1(a)-(b) of [10] respectively allow for univariate serial correlation and for weak correlations across series in the idiosyncratic components. 
serial autocorrelations do not go far in time, I assume that $\operatorname{VAR}(5) \approx \operatorname{VAR}(\infty)$. I therefore estimate idiosyncratic shocks $\mathbf{u}_{t}$ as the regression residuals of a $\operatorname{VAR}(5)$ applied on $\widehat{\boldsymbol{\xi}}_{t}$ 's. Given these idiosyncratic shocks, I estimate $B$ via OLS ${ }^{4}$ by regressing $\widehat{\boldsymbol{\xi}}_{t}$ on $\widehat{\mathbf{u}}_{t-1}$ :

$$
\widehat{B}=\left(\sum_{t=2}^{T} \widehat{\mathbf{u}}_{t-1}^{\prime} \widehat{\mathbf{u}}_{t-1}\right)^{-1}\left(\sum_{t=2}^{T} \widehat{\mathbf{u}}_{t-1}^{\prime} \widehat{\boldsymbol{\xi}}_{t}\right) .
$$

Third, I decompose $\widehat{B}$ in the sum of a rank one matrix $\widehat{\boldsymbol{\beta}} \widehat{\boldsymbol{\gamma}}^{\prime}$ accounting for market wide contagion, and another matrix $\widehat{\Delta}$ accounting for country-specific contagion. As said, I assume the model to respect the condition $\boldsymbol{\beta}^{\prime} \boldsymbol{\delta}_{i}=0, \forall i$. By imposing this identification constraint on estimated parameters I have that ${ }^{5}$

$$
\widehat{\gamma}=\frac{1}{n} \widehat{B}^{\prime} \widehat{\boldsymbol{\beta}}
$$

and

$$
\widehat{\Delta}=\widehat{B}-\widehat{\boldsymbol{\beta}} \widehat{\gamma}^{\prime}
$$

\subsection{Estimation results}

On the thirteen overlapping windows defined in Section 3, the model defined in (1), (2) and (3) is estimated.

Table 4 shows parameter estimates. For scaling reasons, I show the common and idiosyncratic volatilities rather than variances. Moreover, rather than showing the contagion coefficients $\gamma_{i}$, I show the product $\gamma_{i} \sigma_{i}$-this corresponds to the marginal contagion contribution of country $i$ to the volatility of the factor $\phi_{t}$. Important to precise is that total variance effect of common contagion is not equal to the sum of the squares of these marginal effects, since the non zero correlation between idiosyncratic shocks also has an impact on the total contagion. In the last four lines I show the average variance decomposition. ${ }^{6}$ Figures 2 and 3 plot the evolution of these parameters over the considered period.

The period covering 2008 and 2009 (sub-samples 1 to 7) is characterized by a stable pattern of high comovement: the factor loadings are close to each other and, especially at the beginning, idiosyncrasy is a relatively small proportion of total variance. Idiosyncratic volatilities however gradually increase, moving from $10 \%$ to $42 \%$ of explained variance. Common

\footnotetext{
${ }^{4}$ Given the allowed correlation between different idiosyncratic shocks, GLS would produce more accurate results - this will be explored in a next version of the paper.

${ }^{5}$ Since $\boldsymbol{\beta}^{\prime} \boldsymbol{\beta}=n$, one remarks that the identification assumption $\boldsymbol{\beta}^{\prime} \boldsymbol{\delta}_{i}=0$ implies that $\boldsymbol{\gamma}$ can be estimated by regressing $\widehat{B}$ on $\widehat{\boldsymbol{\beta}}$. Indeed, that would produce an estimate $\widehat{\boldsymbol{\gamma}}^{\prime}=\left(\widehat{\boldsymbol{\beta}}^{\prime} \widehat{\boldsymbol{\beta}}\right)^{-1}\left(\widehat{\boldsymbol{\beta}}^{\prime} \widehat{B}\right)=\frac{1}{n} \widehat{\boldsymbol{\beta}}^{\prime} \widehat{B}$, which is equivalent to (5). From this perspective, one may consider $\boldsymbol{\delta}_{i}$ as contagion residuals of country $i$.

${ }^{6}$ That is, the cross-sectional average of univariate variance decompositions. For a country $i$, total variance can come from common shocks $\left(\beta_{i}^{2} \sigma_{v}^{2}\right)$, from common contagion $\left(\beta_{i}^{2} \gamma^{\prime} \Sigma_{u} \gamma\right)$, from idiosyncratic shocks $\left(\sigma_{i}^{2}\right)$ and from idiosyncratic contagion $\left(\boldsymbol{\delta}_{i}^{\prime} \Sigma_{u} \boldsymbol{\delta}_{i}\right)$. The sum of these terms should equal total univariate variance. Therefore, the cross-sectional average of these terms should also equal the cross-sectional average of univariate variances. This is what is meant by average variance decomposition.
} 
contagion is non-existent and idiosyncratic contagion represents no more than $10 \%$ of total variance.

One however observes a clear break once data of the second trimester of 2010 are considered. Those months were the first during which very negative news about Greece, and later about Ireland and Portugal, were received. This is reflected in the estimated parameters, since Greek, Irish and Portuguese idiosyncratic volatilities $\sigma_{i}$ strongly increased. So did their factor loadings relatively to other countries: the three crisis economies do not only produce larger idiosyncratic shocks, but common shocks also have an increased impact.

I suggest two explanations for the observed divergence in factor loadings. First of all, the obtained estimators could reflect what I denote by systematic flight-to-quality dynamics. Under the latter, common shocks have two effects on countries: the usual co-movement impact plus a substitution between bonds of good versus bad countries-negative market news will cause investors to sell risky bonds and substitute them by less risky ones. This dynamic would blow up the factor loadings of countries that are perceived as risky, while counterbalancing those of countries enjoying the perception of being safe. A second possible explanation of the evolution of factor loadings may be that contagion dynamics as defined in [4] are captured. The latter define contagion as excess contemporaneous correlations of idiosyncratic components, under the hypothesis that the fundamental common factor variance is the same before and during the crisis. As shown in Table 4, the standard deviation $\sigma_{v}$ of the common shock nearly doubled between sub-samples 7 and 8. One could thus support the hypothesis that true factor loadings have not changed between both sub-samples, but that since bonds of Greece, Portugal and Ireland are contemporaneously affected by idiosyncratic shocks of all other sovereign bonds, their factor loadings artificially increased when not taking this contemporaneous excess comovement into account. The differences between both explanations should be well understood, since the first focuses on the contemporaneous impact of common shocks, while the second looks at the contemporaneous impact of idiosyncratic shocks.

Including the second trimester of 2010 also generates the appearance of common contagion, as shown in the right panel of Figure 2. Recall that in this context contagion is defined through the Granger causality of idiosyncratic shocks, and not by looking at the contemporaneous correlations. The biggest marginal contributors to the variance of the common contagion term, $\gamma^{\prime} \Sigma_{u} \gamma$, are France, Italy, Portugal, Finland and the Netherlands. Notwithstanding its large idiosyncratic volatility, the marginal impact of Greece to common contagion is rather limited. This supports the idea that, even though investors suffer from their exposure to Greece (which is reflected by the high factor loading), the Greek economy would be too small to make the Euro-zone fail on its own. Bad news on other sovereign bonds, such Portuguese and Italian, who also suffer from negative news, and even bonds from safer countries such as France, Finland or the Netherlands, are much more dangerous for the European stability and therefore have a bigger causal impact on the common factor. Defining systemic risk of a country as the risk of its sovereign bond pushing down the whole Euro-zone sovereign bond market, common contagion coefficients could therefore be interpreted as such. Indeed, one could conclude from the data that France and Italy had the highest systemic risk during 2010.

The results obtained in subsamples 12 and 13 deserve particular attention. As clearly il- 
lustrated in the right panel of Figure 2, the factor loadings undergo some kind of twist in subsample 12. Moreover, common contagion is nearly inexistent, which constrasts with results of the previous and the next subsamples. A possible explanation for this big differences in overlapping panels could be that data are driven by two rather than by only one factor, as already suggested in Figure 1. More particularly, under the hypothesis that there are two factors governing the European bond market, the first one representing the European as a whole and the second accounting only for troubled economies, it could be that the first principal components of subsamples 12 and 13 capture different factors and therefore have inconsistent results. To overcome such problem, the next Section extends the present model to the case with two factors.

\section{A two-factor model}

\subsection{The model}

As Figure 1 of Section 3 indicates, bond returns during the midst of the crisis seem to be characterized by two factors rather than by one. This idea is very intuitive, since it understates the decoupling in the sovereign bond market, with a factor for bad economies and another one for the good ones. The focus of investors and of media has indeed been much more on the spread of a country's government bond yield with respect to the yield of Germany, rather than on the yield of the country itself. For underlying macroeconomic reasons such as a very positive trade balance, low public and private debt, high productivity or low unemployment levels, Germany is considered as the safest country of the Eurozone. Therefore, the riskiness of a country has been measured by the distance of its government bond yields compared to Germany's, and as long as a country is perceived safe by markets, spreads have remained low and co-movement with Germany remains high. However, once investors consider that the default risk of a country is too high, there is a decoupling with respect to Germany, and one could support the hypothesis that there are two groups of countries: the less risky ones, comoving with Germany, and the risky ones, driven by a second factor.

The one-factor model might therefore not be sufficient to accurately describe the crisis. This became already apparent in the previous Section, since the behaviour of sub-samples 11, 12 and 13 is very different, and one may wonder whether the model is not identifying different factors between each of these sub-samples.

I propose the following two-factor model for the demeaned bond returns $x_{i, t}$ :

$$
x_{i, t}=\beta_{1 i} \phi_{1, t}+\beta_{2 i} \phi_{2, t}+\zeta_{i, t},
$$

where $\phi_{1, t}$ is the factor accounting for the European economy as a whole, including Germany, and $\phi_{2, t}$ is a factor on which Germany is imposed to have a loading equal to zero, i.e. $\beta_{2 i^{*}}=0$, where $i^{*}$ is the index corresponding to Germany. Loosely, $\phi_{2, t}$ can be understood as capturing the difference with respect to Germany, or as a troubled economy factor. As in Section 4, these 
Figure 2: One-factor model: factor loadings and marginal common contagion effects

Factor loadings $\beta_{i}$

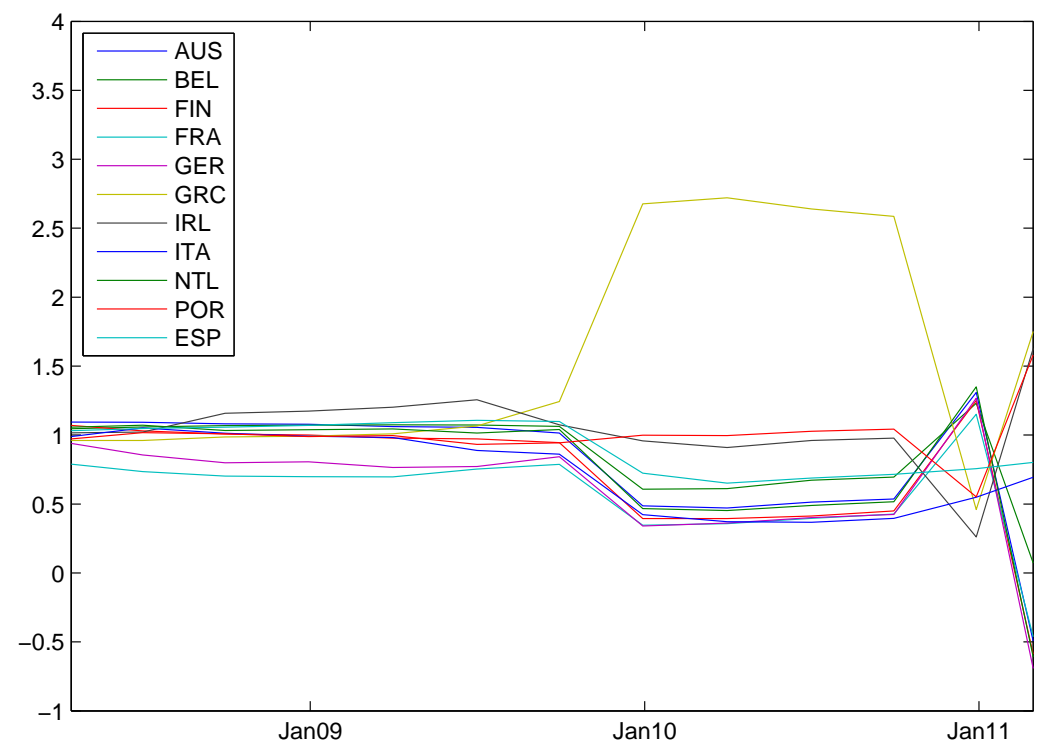

Common contagion $\gamma_{i} \sigma_{i}$

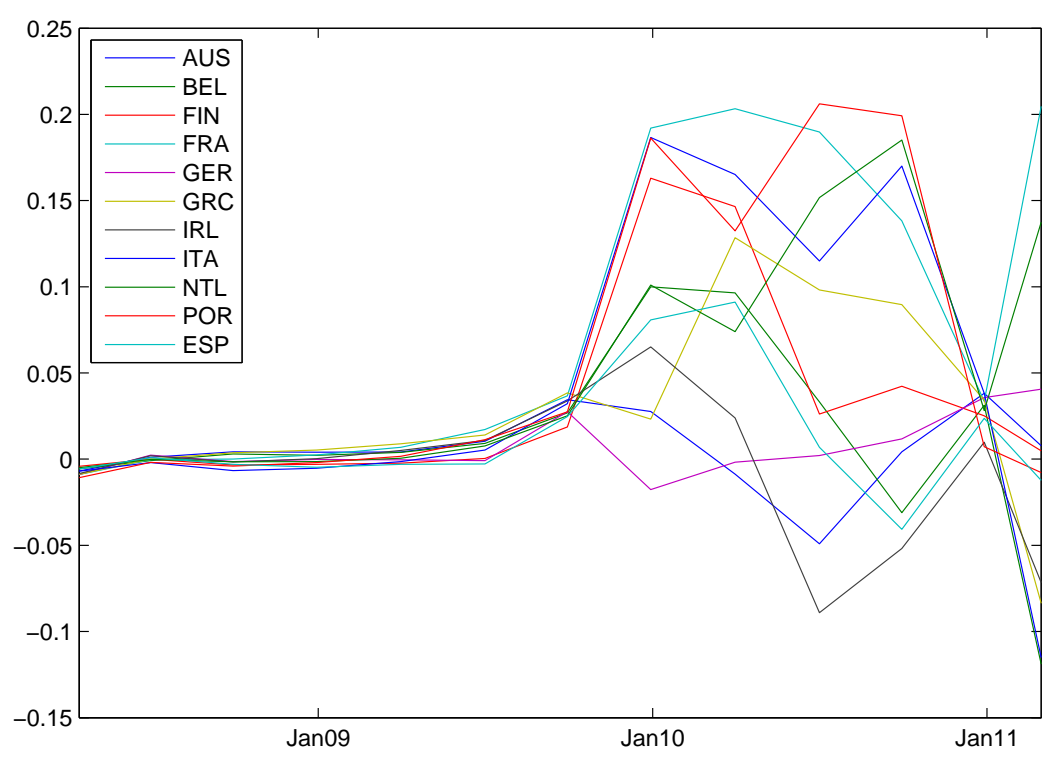

Plots of paramaters of Table 4: factor loadings $\beta_{i}$ (left), common contagion contributions $\gamma_{i} \sigma_{i}$ (right). The abcissa represents the central date of the considered time window. 
Figure 3: One-factor model: idiosyncratic volatilities and variance decomposition

Idiosyncratic volatilities $\sigma_{i}$

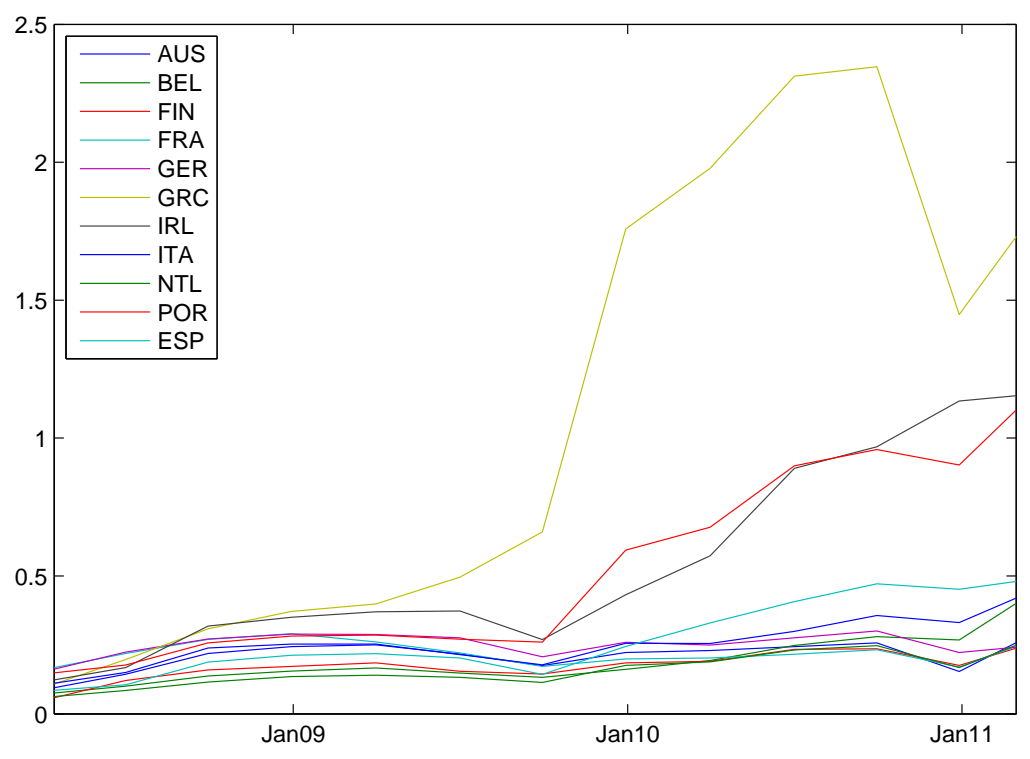

Variance decomposition

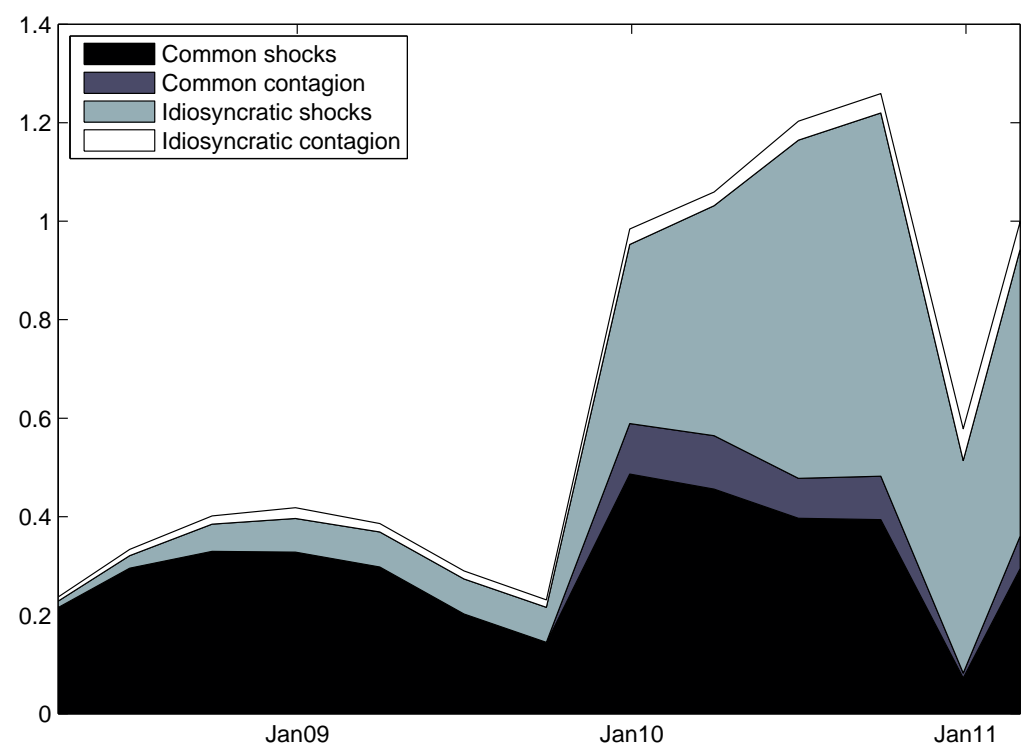

Plots of parameters of Table 4: idiosyncratic volatilities $\sigma_{i}$ (left) and total variance decomposition (right). The abscissa represents the central date of the considered time window. 
terms are not common and idiosyncratic in the traditional sense, but are both allowed to suffer from contagion arising from truly idiosyncratic shocks. Indeed, the country-specific term $\zeta_{i, t}$ is modelled as in (3), and the first two factors are modelled as

$$
\phi_{1, t}=v_{1, t}+\rho_{12} v_{2, t-1}+\sum_{k=1}^{n} \gamma_{k 1} u_{k, t-1}
$$

and

$$
\phi_{2, t}=v_{2, t}+\rho_{21} v_{1, t-1}+\sum_{k=1}^{n} \gamma_{k 2} u_{k, t-1},
$$

where $v_{1, t}, v_{2, t}$ and $u_{i, t}$ respectively are common and idiosyncratic shocks, satisfying unconditional orthogonality conditions, namely that $\forall i, j \in\{1, \ldots, n\}, \forall t, s \in \mathbb{Z}$ and for $k, l=1,2$ : $\mathrm{E}\left[u_{i, t-s} u_{j, t}\right]=0, \mathrm{E}\left[u_{i, t-s} v_{l, t}\right]=0$ and $\mathrm{E}\left[v_{k, t-s} v_{l, t}\right]=0$.

As it is clear in (8) and (9), working with a two-factor model allows to add a layer of complexity. Indeed, I do not only allow the common factor to suffer coming from idiosyncratic shocks, but I can also assess contagion arising from the other factor. The reason for this crossed causality between shocks of the first and second factor, is that one may imagine that the news shared by the group of safe countries affects the risky ones, or vice versa. Hence, although Germany does not load on the second factor, it is still allowed to suffer from contagion arising from troubled economies, through the coefficient $\rho_{21}$.

\subsection{Estimation procedure}

Similarly to (4), I can write

$$
\mathbf{x}_{t}=\boldsymbol{\beta} \mathbf{f}_{t}+\mathbf{u}_{t}+B \mathbf{u}_{t-1},
$$

where $\mathbf{f}_{t}=\mathbf{v}_{t}+R \mathbf{v}_{t-1}, \boldsymbol{\beta}=\left(\boldsymbol{\beta}_{1}, \boldsymbol{\beta}_{2}\right), \mathbf{v}_{t}=\left(v_{1, t}, v_{2, t}\right)^{\prime}$ and $R$ is a matrix having zeros on the diagonal but $\rho_{12}$ and $\rho_{21}$ as off-diagonal elements. As in (4), $B=\boldsymbol{\beta} \boldsymbol{\gamma}^{\prime}+\Delta$, where $\gamma=\left(\gamma_{1}, \gamma_{2}\right)$. (10) is now a static factor model with two common factors and with static common components $\chi_{t}=\boldsymbol{\beta} \mathbf{f}_{t}$ and dynamic idiosyncratic components $\boldsymbol{\xi}_{t}=\mathbf{u}_{t}+B \mathbf{u}_{t-1}$. Estimating (10) is a problem of $2 n+2+2+2 n+n^{2}+n(n+1) / 2$ unknowns: $2 n$ factor loadings $\boldsymbol{\beta}_{1}$ and $\boldsymbol{\beta}_{2}, 2$ factor variances $\sigma_{v 1}^{2}$ and $\sigma_{v 2}^{2}, 2$ factor moving average coefficients in $R, 2 n$ common contagion coefficients $\gamma_{1}$ and $\gamma_{2}, n^{2}$ idiosyncratic contagion coefficients of $\Delta$ and $n(n+1) / 2$ elements in the idiosyncratic variance matrix $\Sigma_{u}$.

Similar identification constraints hold as in the one-factor model. For exactly identifying the factor model, I assume that $\boldsymbol{\beta}_{l}^{\prime} \boldsymbol{\beta}_{l}=n$, for $l=1,2$. To distinguish common and idiosyncratic contagion, I assume that $\boldsymbol{\beta}_{1} \boldsymbol{\delta}_{i}=\boldsymbol{\beta}_{2} \boldsymbol{\delta}_{i}=0, \forall i$. The identification constraint particular to the two-factor model is that I will assume Germany does not load on the second factor. This is important since factor models are identified up to a static rotation matrix.

The estimation goes in four steps. 
First, I estimate $\boldsymbol{\beta}, \mathbf{f}_{t}$ and $\boldsymbol{\xi}_{t}$ by applying the static two-factor model of [10] to the $\mathbf{x}_{t}$ 's. More specifically, call $\mathbf{b}=\left(\mathbf{b}_{1}, \mathbf{b}_{2}\right)$ and $\tilde{\mathbf{f}}_{t}=\left(\tilde{f}_{1, t}, \tilde{f}_{2, t}\right)^{\prime}$ the loadings and the first two principal components given by the static factor model, such that $\operatorname{var}\left(\tilde{\mathbf{f}}_{t}\right)=I_{2}$. The static factors are defined up to a static rotation, i.e. given a static rotation matrix

$$
r=\left(\begin{array}{cc}
\cos \theta & -\sin \theta \\
\sin \theta & \cos \theta
\end{array}\right)
$$

one has that $\mathbf{b} \tilde{\mathbf{f}}_{t}=\mathbf{b} r^{\prime} r \tilde{\mathbf{f}}_{t}$ and one could define another model with factor loadings $\mathbf{b} r^{\prime}$ and factors $r \tilde{\mathbf{f}}_{t}$. I choose the rotation angle $\theta^{*}$ such that Germany does not load on the second factor. This is achieved if $b_{1 i^{*}} \sin \theta^{*}+b_{2 i^{*}} \cos \theta^{*}=0$, i.e. if

$$
\theta^{*}=\arctan \left(-\frac{b_{2 i^{*}}}{b_{1 i^{*}}}\right)
$$

Define $r^{*}$ the corresponding rotation matrix. The newly obtained factor loadings and factors are then $\mathbf{b} r^{* \prime}$ and $r^{*} \tilde{\mathbf{f}}_{t}$, which can rescaled to $\boldsymbol{\beta}$ and $\mathbf{f}_{t}$ such that $\boldsymbol{\beta}_{1}^{\prime} \boldsymbol{\beta}_{1}=\boldsymbol{\beta}_{2}^{\prime} \boldsymbol{\beta}_{2}=n$. Since I imposed that $\operatorname{var}\left(\tilde{f}_{t}\right)=I_{2}$, one still has that $\operatorname{var}\left(r^{*} \tilde{f}_{t}\right)=I_{2}$ and hence that $\mathrm{E}\left[f_{1, t} f_{2, t}\right]=0$, which is consistent with (8) and (9). ${ }^{7}$

Second, I identify common shocks $v_{1, t}$ and $v_{2, t}$ and common factor contagion coefficients $R$. Since each of the factors is only affected by the past shocks of the other factor, I propose to work with the following iterative procedure. Define as the initial estimates of the common shocks $\widehat{v}_{1, t}^{(0)}=\widehat{f}_{1, t}$ and $\widehat{v}_{2, t}^{(0)}=\widehat{f}_{2, t}$. Then, for the $k$ th iteration, define the OLS estimators of the regression,

$$
\widehat{\rho}_{21}^{(k)}=\left(\sum_{t=2}^{T}\left(\widehat{v}_{2, t-1}^{(k)}\right)^{2}\right)^{-1}\left(\sum_{t=2}^{T} \widehat{v}_{2, t-1}^{(k)} \widehat{f}_{1, t}\right),
$$

and

$$
\widehat{\rho}_{12}^{(k)}=\left(\sum_{t=2}^{T}\left(\widehat{v}_{1, t-1}^{(k)}\right)^{2}\right)^{-1}\left(\sum_{t=2}^{T} \widehat{v}_{1, t-1}^{(k)} \widehat{f}_{2, t}\right) .
$$

This then allows to update $\widehat{v}_{1, t}^{(k+1)}=\widehat{f}_{1, t}-\widehat{\rho}_{21}^{(k)} \widehat{v}_{2, t-1}^{(k)}$ and similarly for the other factor. The procedure is repeated parameters do not deviate by more than $5 \%$ compared to the previous estimate, which happens after three iterations for both factors.

Third, I estimate a VMA(1) on idiosyncratic components $\boldsymbol{\xi}_{t}$ to estimate idiosyncratic variances $\sigma_{i}^{2}$ and non decomposed contagion coefficients $B$. The procedure used is the same as in Section 4 .

\footnotetext{
${ }^{7}$ If, on top of modelling cross causality $\rho_{12}$ and $\rho_{21}$, I would also have included univariate moving average dynamics $\rho_{11}$ and $\rho_{22}$, one would theoretically have that $\mathrm{E}\left[f_{1, t} f_{2, t}\right] \neq 0$. This would make the rotation exercise much more complicated-one needs a rotation such that only innovations $v_{1, t}$ and $v_{2, t}$ are orthogonal, and not the factors themselves. Although this is a very interesting field of research, it goes beyond the main objective of the present paper.
} 
Fourth, I estimate common and idiosyncratic contagion coefficients. Since similar constraints are imposed as in the previous Section, one has that

$$
\widehat{\gamma}=\frac{1}{n} \widehat{B}^{\prime} \widehat{\boldsymbol{\beta}}
$$

with $\gamma=\left(\gamma_{1}, \gamma_{2}\right)$ and that

$$
\widehat{\Delta}=\widehat{B}-\widehat{\boldsymbol{\beta}} \widehat{\gamma}^{\prime}
$$

\subsection{Estimation results}

Estimated parameters are shown in Table 5 and plotted in Figures 4, 5 and 6.

The results are very complementary to those of the one-factor model. First and foremost, when looking at the overall evolution of parameters, one does not observe any jumps or twists at the final subsamples. This seems a good indicator that the latent factors capture the same dynamics throughout the whole period.

When focusing on the factor loadings shown in Figure 4, one observes an interesting evolution compared to the one-factor model. First, it seems that —at least during 2010 — the first principal component of one-factor model is very correlated with the second factor in the twofactor model. Indeed, factor loadings follow a very similar behaviour: Greece has the highest factor loading, followed by Portugal, Ireland, Spain and Italy, as in the one-factor model. Figure 6 also illustrates that the jump in factor variance happening in 2010 can be allocated to the second factor. Whether the single factor of 2008 and 2009 corresponds rather to the first or the second factor is difficult to say based on the estimated parameters: in both cases they are stable and the factor variances exhibit similar patterns. Nevertheless, given that Germany is imposed not to load on the second factor, it intuitively makes more sense to prescribe the single factor identified for 2008 and 2009 to the first factor in the two-factor model.

The loadings on the first factor starting in 2010 exhibit an interesting pattern. The loadings of those countries that were most under pressure gradually plummet, first to become equal to zero and then to become very negative. The sequence of this decline is very coherent with how markets integrated the riskiness of these countries: first Greece, and then in time followed by Portugal, Ireland, Spain and Italy. I find this result particularly informative about the question whether a decoupling took place. Indeed, if a pure decoupling had taken place, then the loadings of these countries would have gone to zero, but they would not have become so negative. One interpretation of this evolution is that there are systematic flight-to-quality dynamics. Such a large divergence in factor loadings, with positive and negative signs, is indeed coherent with the hypothesis of systematic flight-to-quality, under which a market shock induces investors to substitute risky bonds against safer. Another explanation for this pattern could be that investors are convinced that a break-up of the single currency zone is a good solution. In that case, news that troubled countries will not be bailed out is good for Germany but bad for Greece. In a way, it could mean that investors consider the European economies as antagonistic: what is good news for the strong economies is bad for the weak, and vice 
versa. It is important to properly distinguish the meaning of both explanations: the flight-toquality explanation is purely behavioural and arises from portfolio risk management decisions, whereas the break-up explanation supports a speculative view on market movements.

As shown in Table 5 and in Figure 6, contagion dynamics coming from idiosyncratic shocks are nearly non existing: both common and idiosyncratic contagion explain a very little part of total variance. In a way, this is confirmed by Figure 5, where there is no clear pattern and where positive and negative contagion seem to offset each other. Factor contagion however shows an interesting result. On the one hand, contagion from troubled economies to safe economies is very small. This means that bond price movements of safe countries are not affected by news of bad countries. On the other hand, what happens in good economies strongly affects the weak country factor: in 2010 this dynamic explained around $10 \%$ of total variance. The sign of $\rho_{21}$ suggests a similar story as what one can tell for the evolution of factor loadings: negative shocks in the strong economies have a positive impact on the weak ones, and vice versa.

The importance of idiosyncratic variance, finally, is much lower in the two- than in the one-factor model. The big increase in idiosyncratic variance of 2010 can be associated to both factors and their interaction.

\section{Conclusion}

In this paper, I investigated the interactions between comovement and idiosyncrasy in the European sovereign bond market. A one-factor model suggests the presence of common contagion during 2010. A two-factor model, which distinguishes between the common dynamics of safe and troubled economies, nuances the picture: safe countries did not jointly suffer from contagion coming from troubled economies. On the contrary, returns on government bonds of troubled economies were influenced by news of safe countries.

The considered model raises several further research opportunities. First of all, it would be interesting to include other time series in the same model, such as returns on corporate bonds or equity returns, and assess the existence of contagion across different markets. From this perspective, one could evaluate whether the sovereign bond market is leading or lagging other markets. Second, one could extend the modelling philosophy from first to second order moments. The question whether idiosyncratic news affect the variance of the common factor is indeed very complementary to the present paper. 
Figure 4: Two-factor model: factor loadings

Factor loadings $\beta_{1 i}$

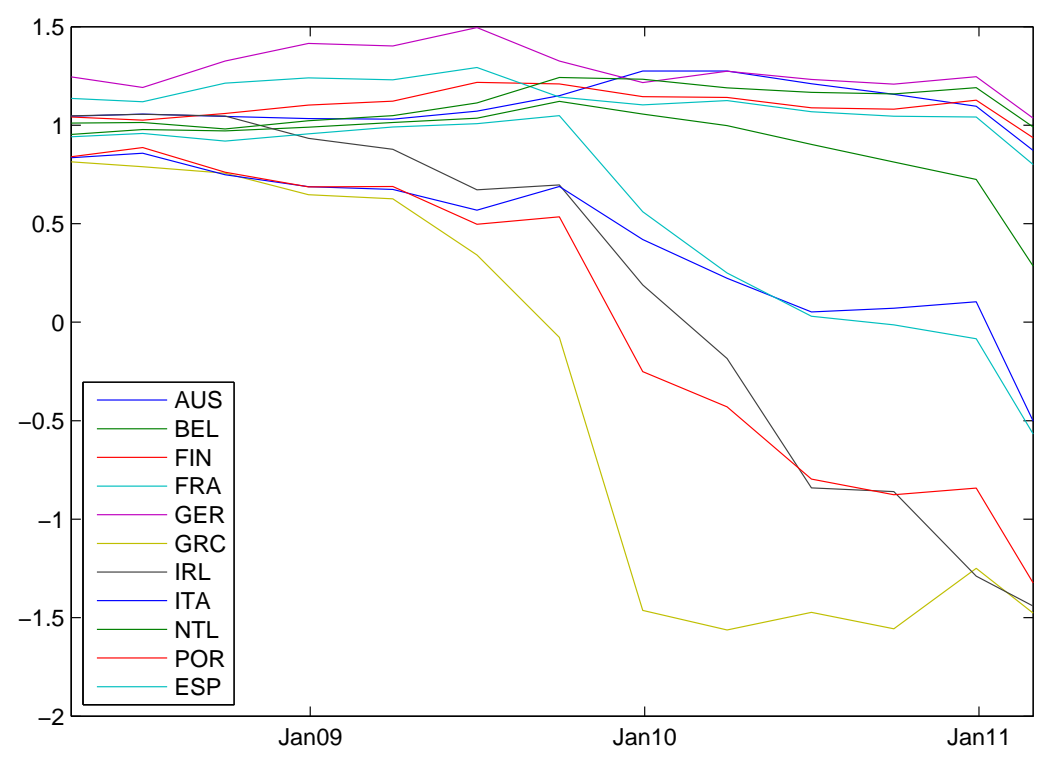

Factor loadings $\beta_{2 i}$

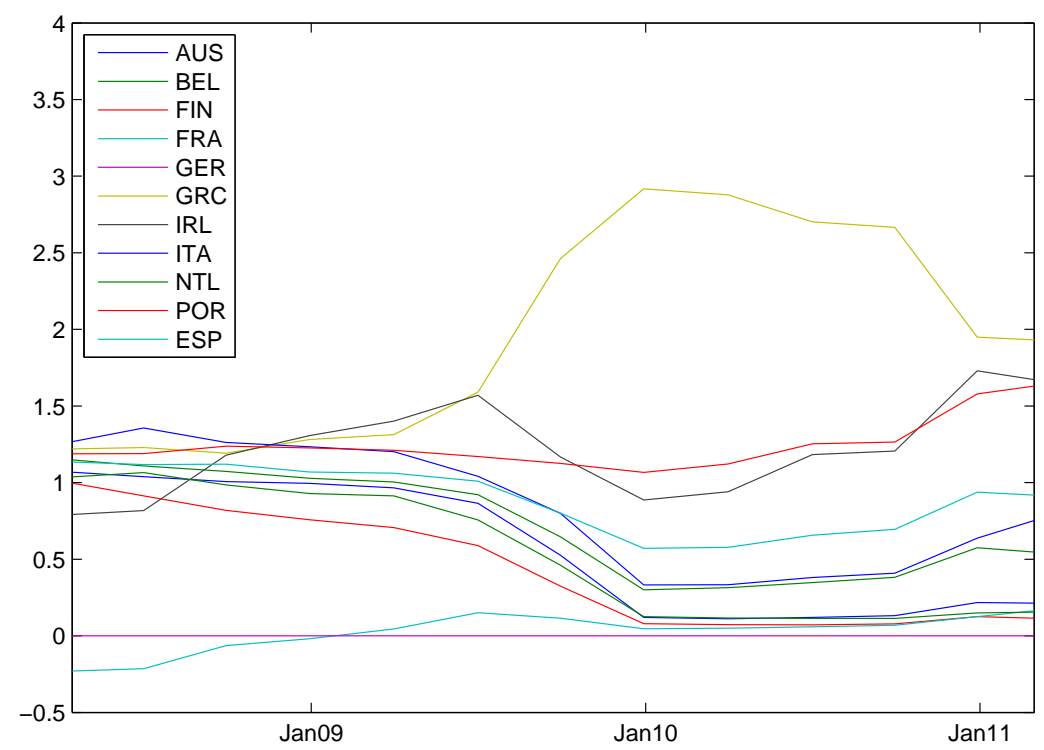

Plots of parameters of Table 5. Factor loadings $\beta_{1 i}$ (left) and $\beta_{2 i}$ (right). The abscissa represents the central date of the considered time window. 
Figure 5: Two-factor model: marginal common and factor contagion effects

Common contagion $\gamma_{1 i} \sigma_{i}$

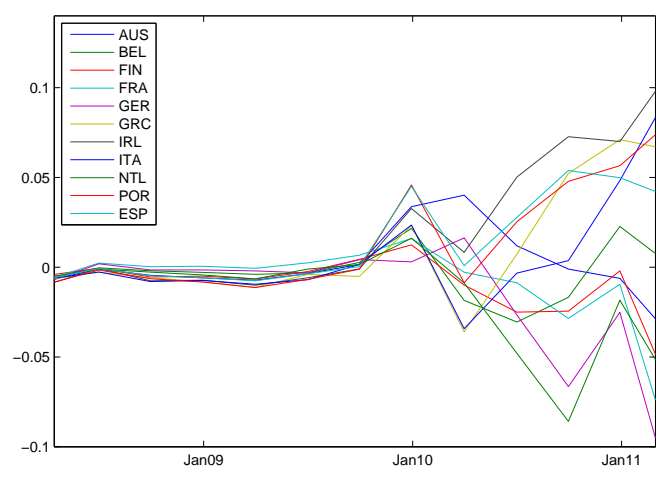

Common contagion $\gamma_{2 i} \sigma_{i}$

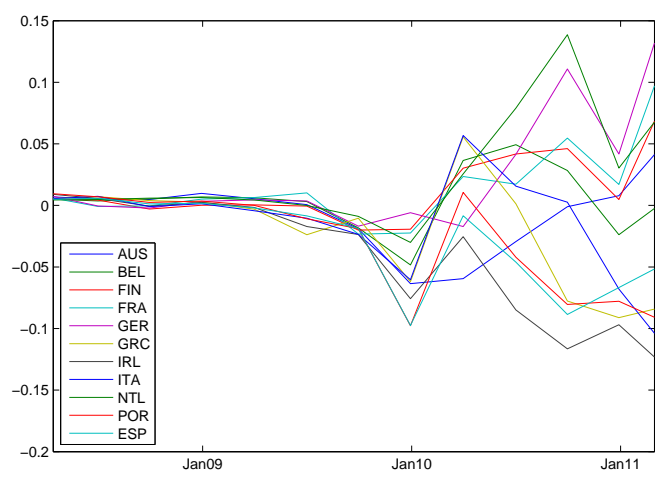

Factor contagion $\rho_{12} \sigma_{v 1}$ and $\rho_{21} \sigma_{v 2}$

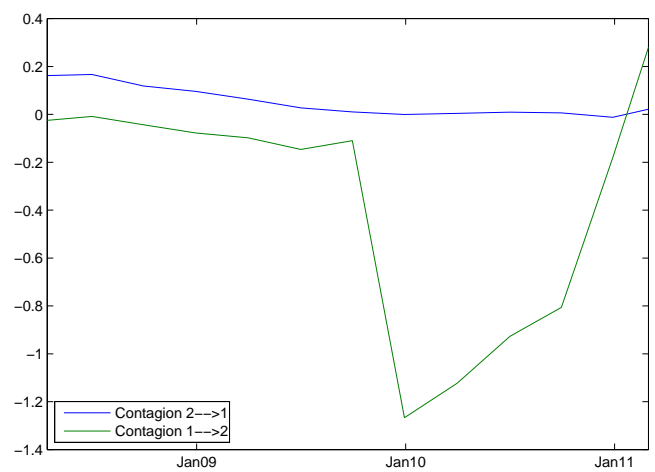

Plots of parameters of Table 5. Common contagion contributions $\gamma_{1 i} \sigma_{i}$ (up) and $\gamma_{2 i} \sigma_{i}$ (middle). Factor contagion contributions (down). The abscissa represents the central date of the considered time window. 
Figure 6: Two-factor model: idiosyncratic volatilities and variance decomposition

Common contagion $\sigma_{i}$

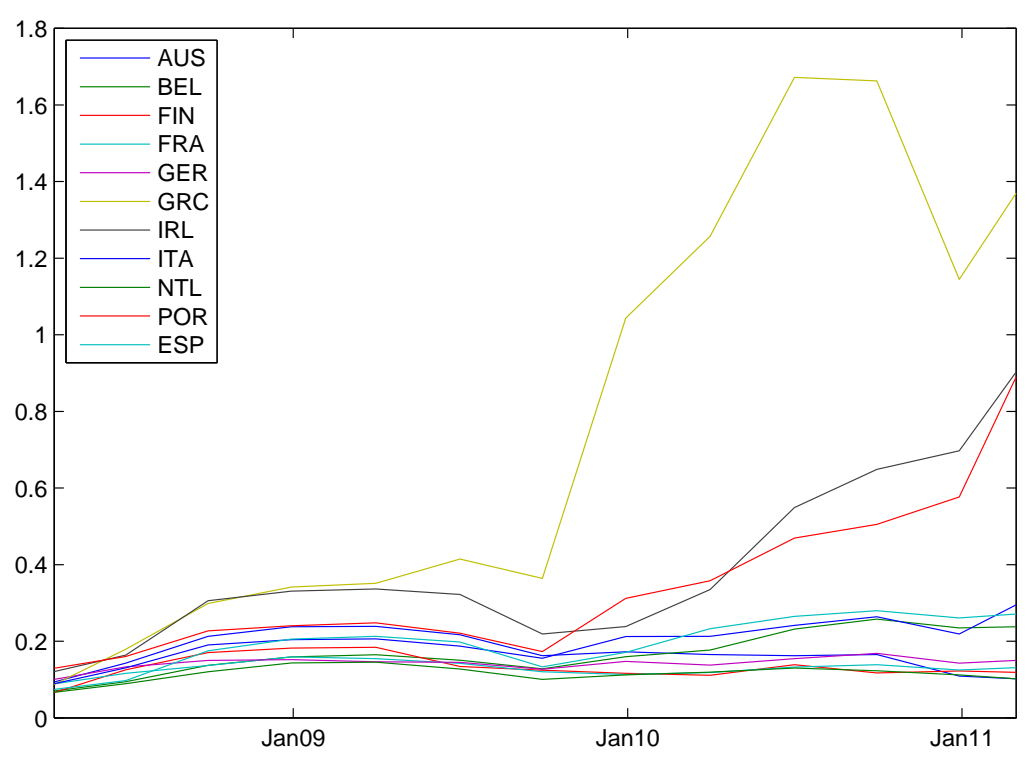

Variance decomposition

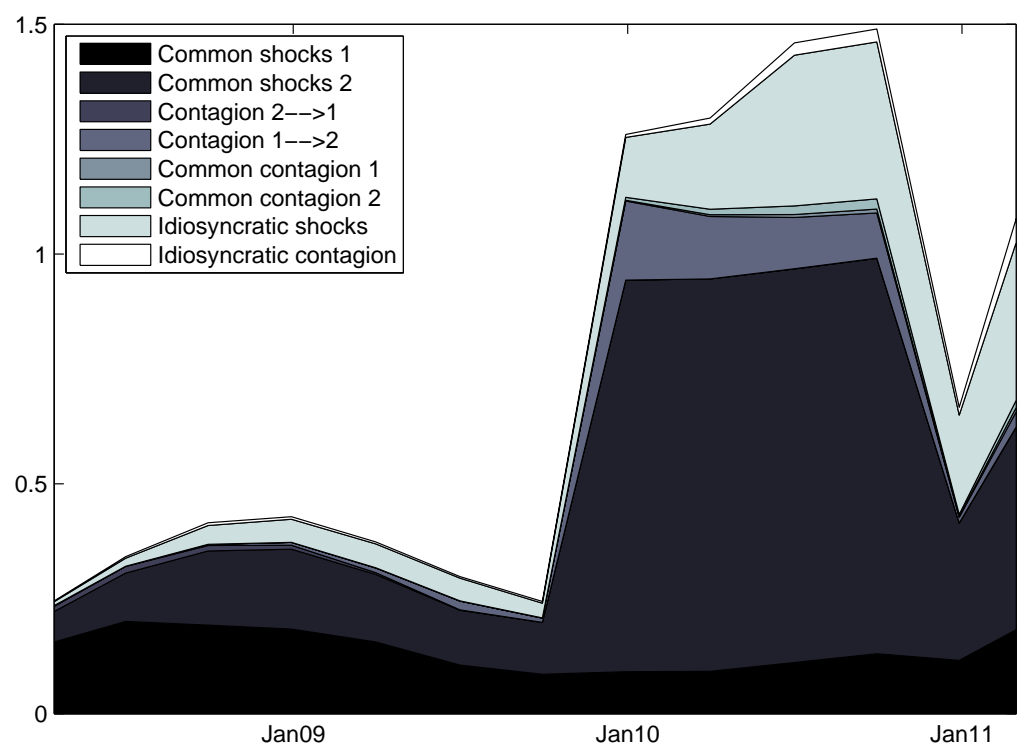

Plots of parameters of Table 5. Up, the idiosyncratic volatilities $\sigma_{i}$. Down, the variance decomposition. The abscissa represents the central date of the considered time window. 


\section{References}

[1] K.-H. Bae, G. A. Karolyi, and R. M. Stulz. A new approach to measuring financial contagion. Review of Financial Studies, 16:717-763, 2003.

[2] Mardi Dungey, Renée A. Fry, Brenda Gonzalez-Hermosillo, and Vance L. Martin. International contagion effects from the russian crisis and the 1tcm near-collapse. IMF Working Paper 02/74, 2002.

[3] Mardi Dungey, Renée A. Fry, Brenda Gonzalez-Hermosillo, and Vance L. Martin. Empirical modelling of contagion: A review of methodologies. Quantitative Finance, 5:9$24,2005$.

[4] Mardi Dungey, Renée A. Fry, Brenda Gonzalez-Hermosillo, and Vance L. Martin. Transmission of Financial Crises and Contagion: A Latent Factor Approach. Oxford University Press, 2011.

[5] Mardi Dungey and Demosthenes N. Tambakis, editors. Identifying International Contagion: Process and Challenges. Oxford University Press, 2005.

[6] C. A. Favero and F. Giavazzi. Is the international propagation of financial shocks nonlinear? evidence from the erm. Journal of International Economics, pages 231-246, 2002.

[7] K. J. Forbes and R. Rigobon. No contagion, only interdependence: Measuring stock market comovements. Journal of Finance, 57:2223-2261, 2002.

[8] Robert A. Mundell. A theory of optimal currency areas. American Economic Review, 1961.

[9] L. Pastor and R. F. Stambaugh. Liquidity risk and expected stock returns. Journal of Political Economy, 111:642-685, 2003.

[10] J. Stock and M. Watson. Forecasting using principal components from a large number of predictors. Journal of the American Statistical Association, 47:1167-1179, 2002b. 


\section{Appendix to Chapter 3}

Figure 7: Evolution of sovereign bond yields

Average

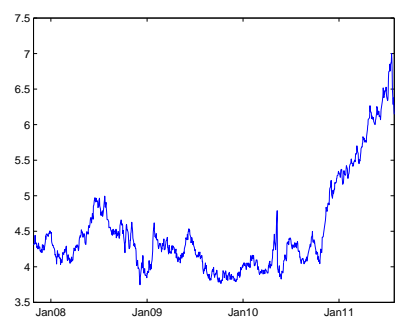

Finland

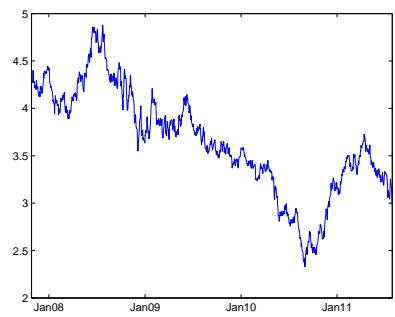

Netherlands

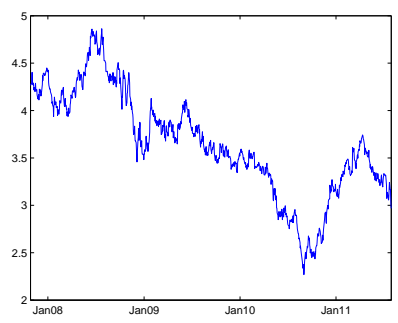

Portugal

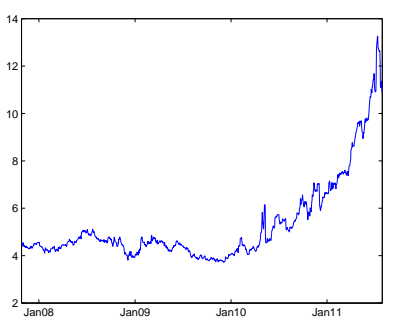

Austria

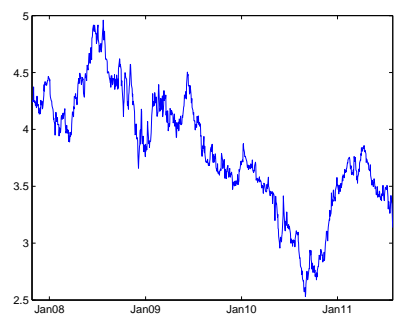

France

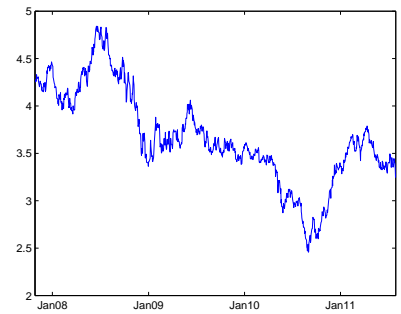

Greece

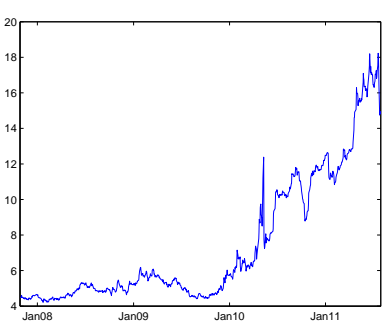

Italy

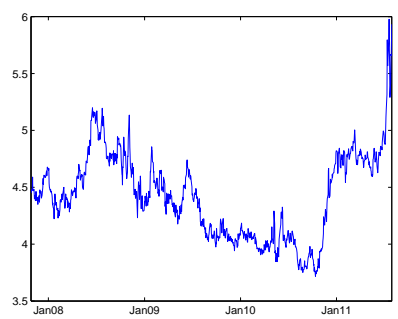

Belgium

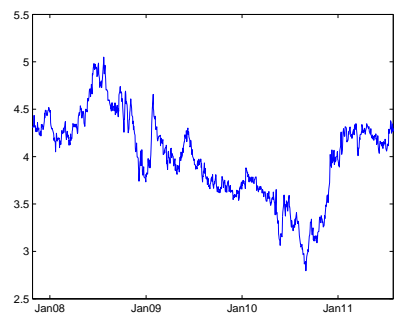

Germany

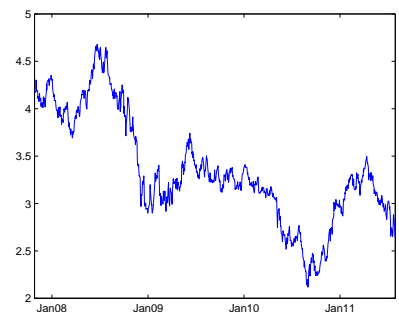

Ireland

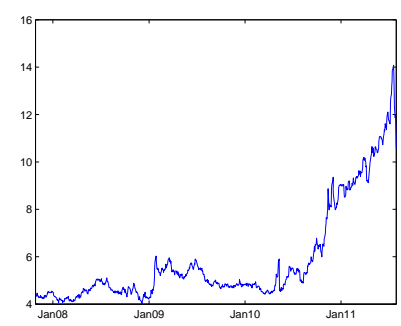

Spain

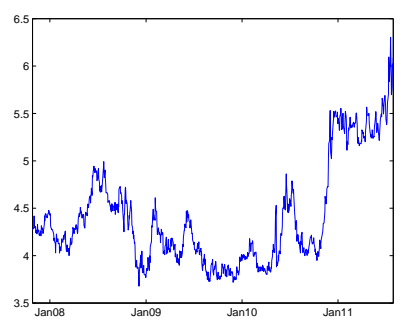

Evolution of sovereign bond yields $y_{i, t}$ of the $n=11$ countries considered. The upper right panel represents the arithmetic average, $\bar{y}_{t}=\frac{1}{n} \sum_{i=1}^{n} y_{i, t}$. All data are multiplied by 100 . 


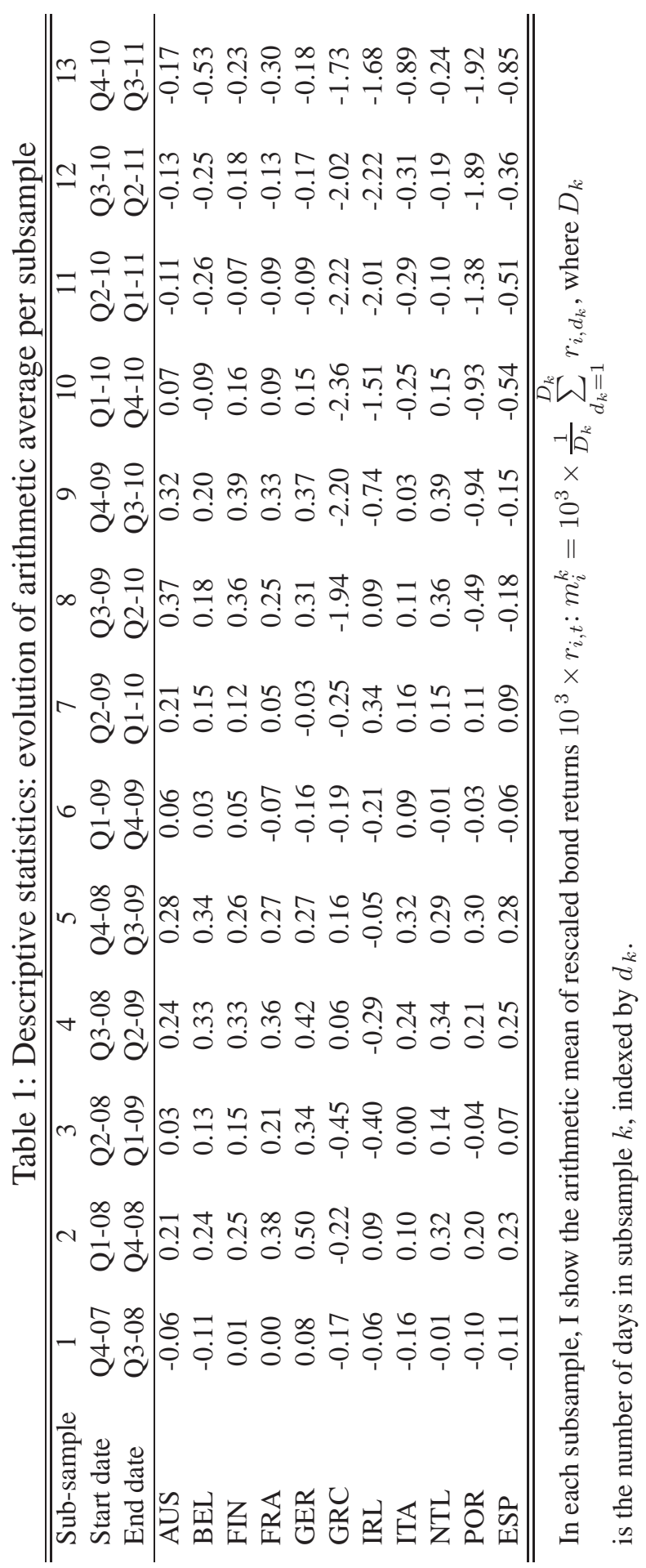




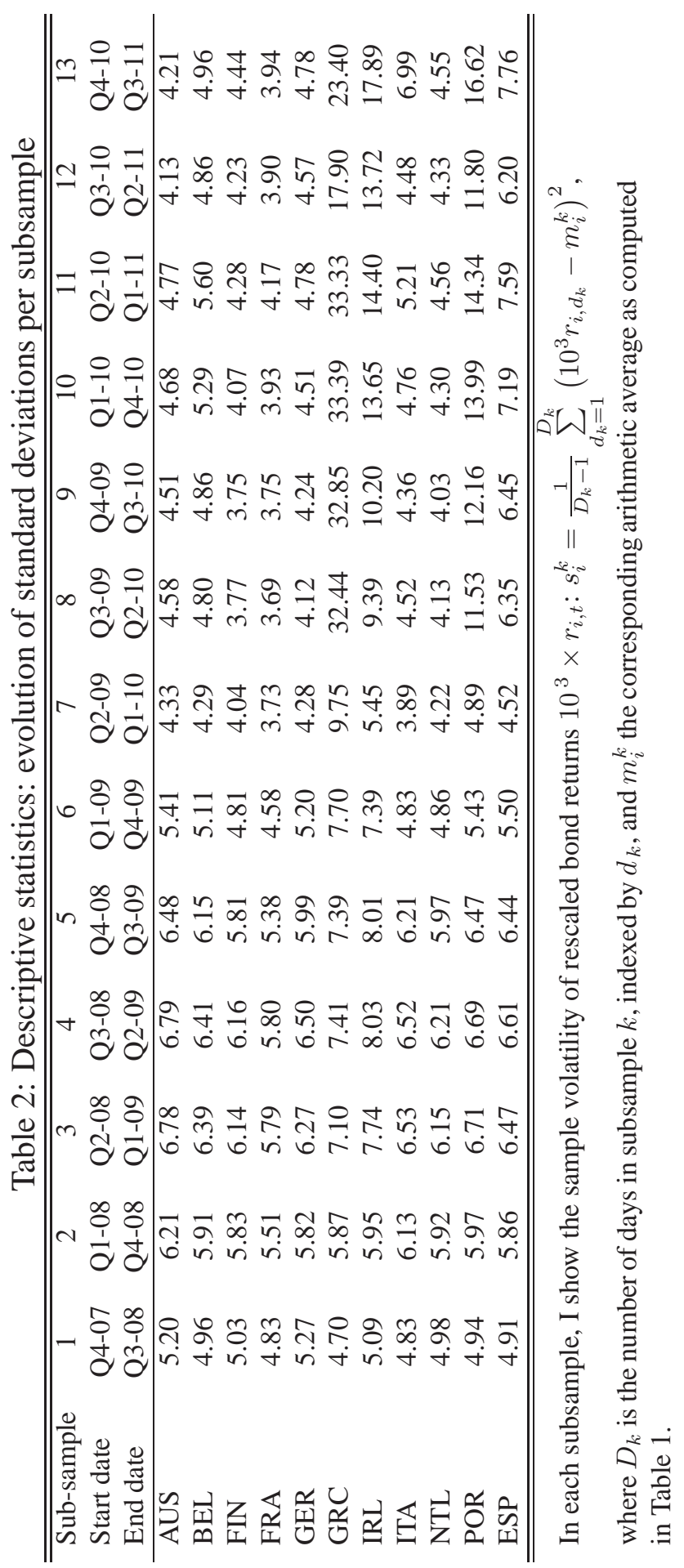




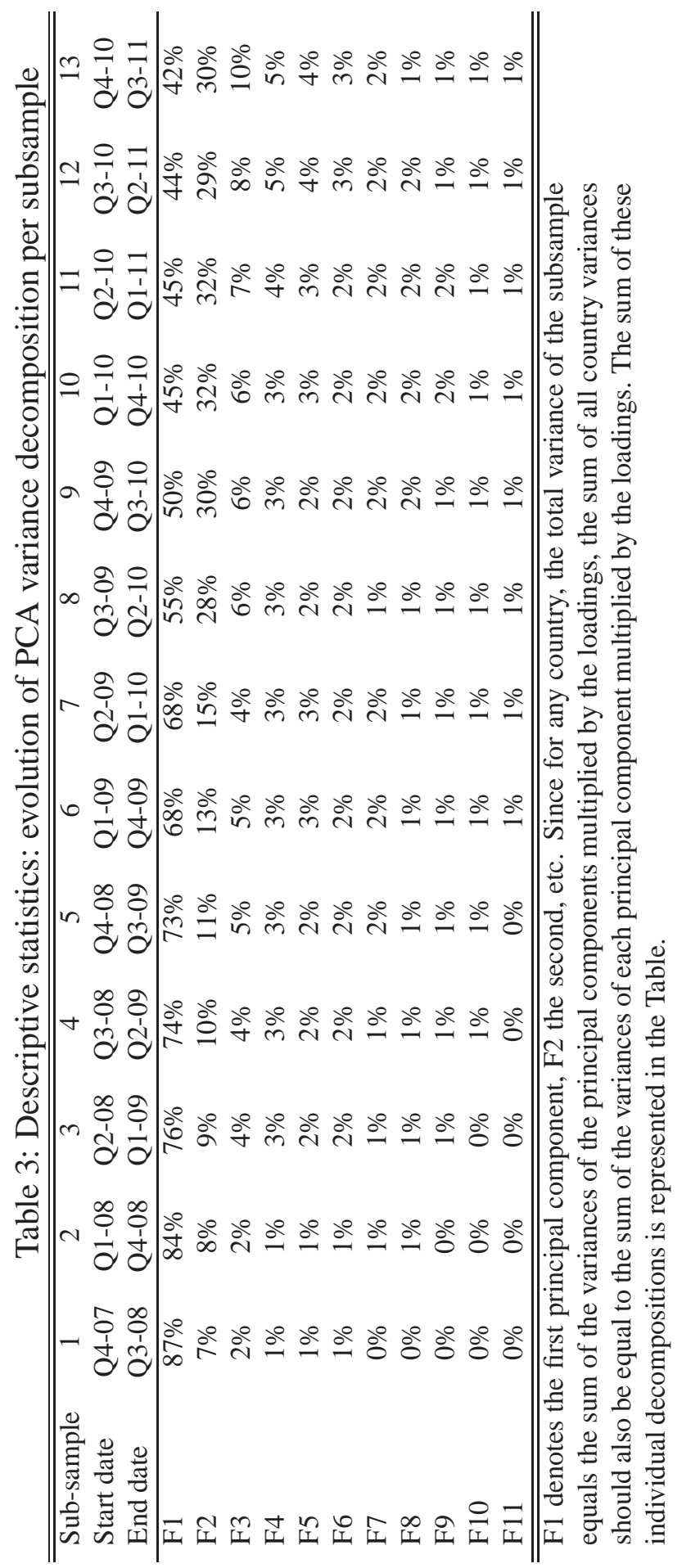




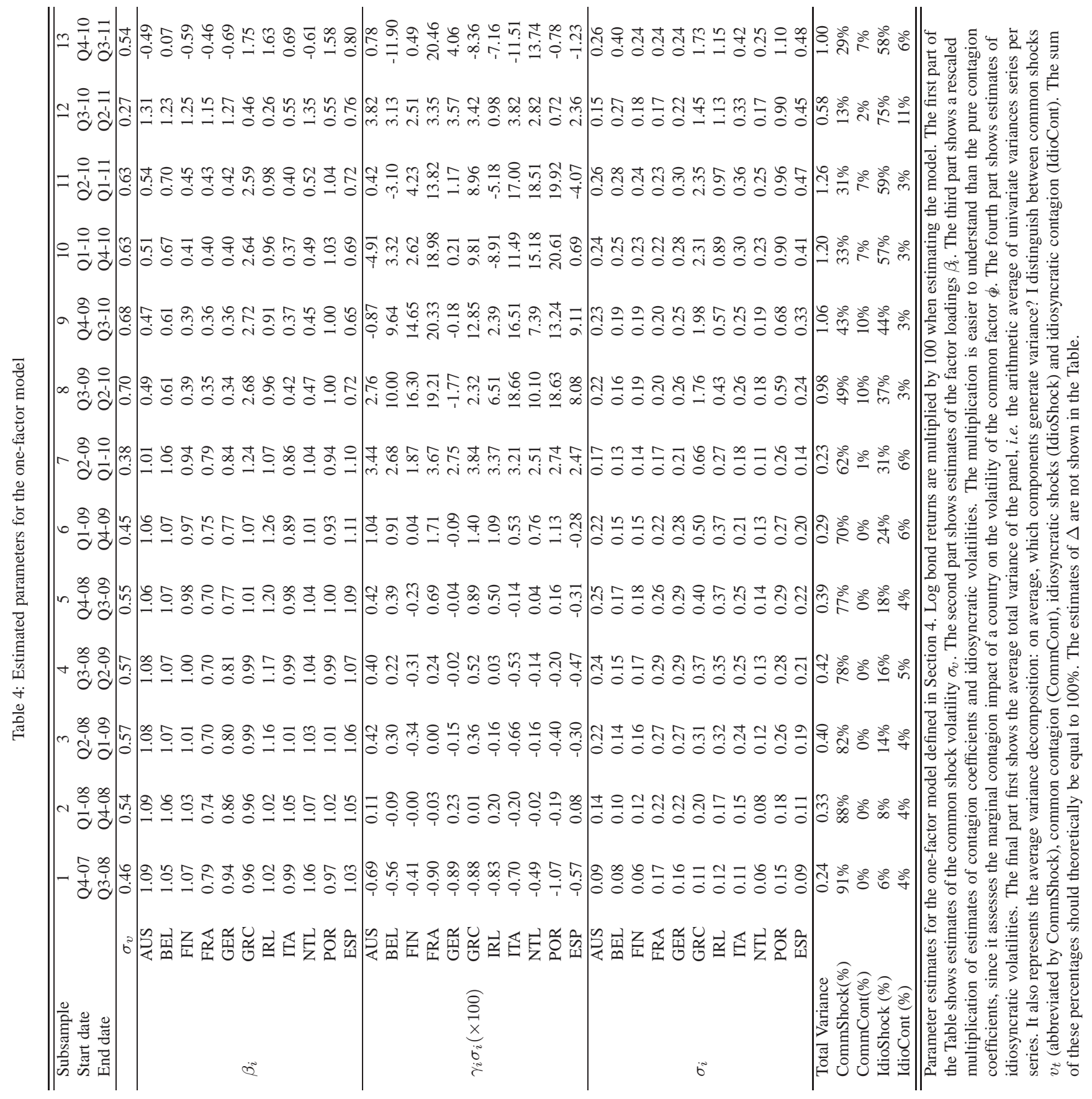




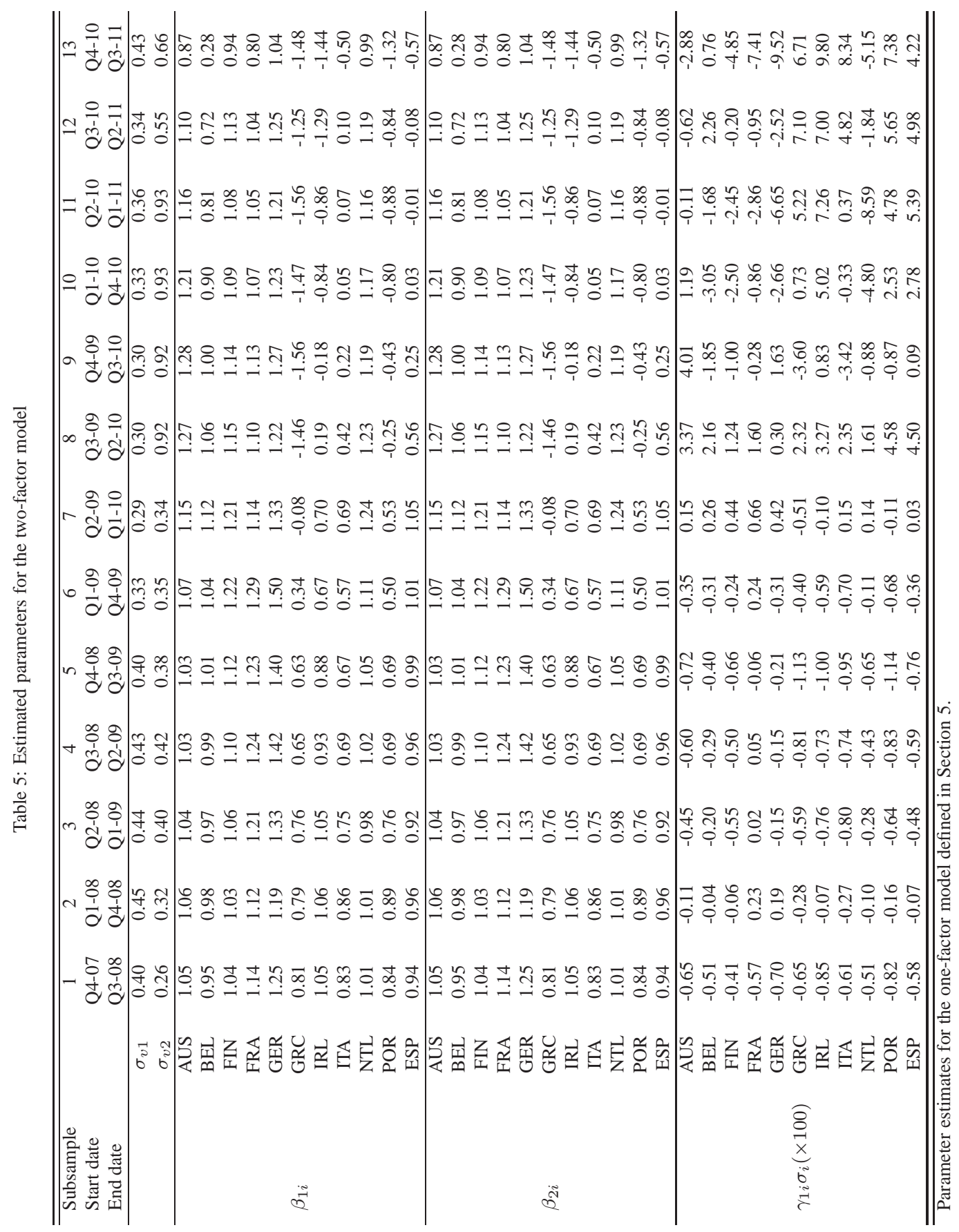




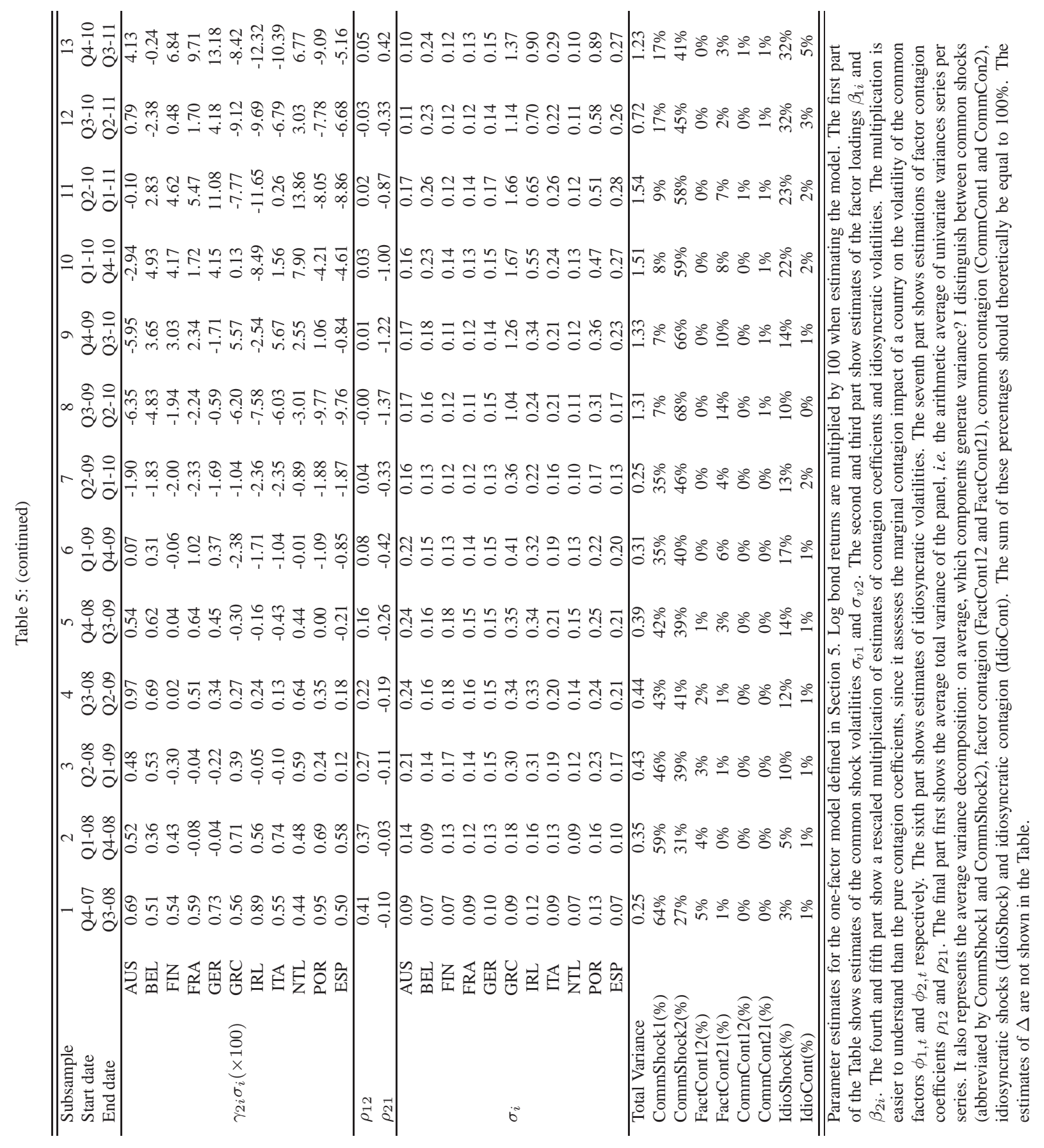

